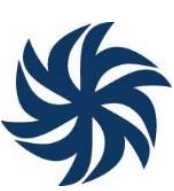

\title{
CANDIDATOS E ELEITOS DEPUTADOS ESTADUAIS NO BRASIL: PARA ONDE VAI A REPRESENTAÇÃO POLÍTICA? (1998-2018)
}

\author{
SUCCESSFUL AND UNSUCCESSFUL CANDIDATES TO STATE \\ REPRESENTATIVES IN BRAZIL: WHERE WILL GO THE POLITICAL \\ REPRESENTATION? (1998-2018)
}

\section{CANDIDATOS EXITOSOS Y NO EXITOSOS A REPRESENTACIÓN PROVINCIAL EN BRASIL: ¿A DÓNDE IRÁ LA REPRESENTACIÓN POLÍTICA? (1998-2018)}

\author{
Tiago Alexandre Leme Barbosa* \\ Bruno Marques Schaefer**
}

\begin{abstract}
Resumo: O trabalho analisa a evolução do perfil social dos candidatos e eleitos para o cargo de deputado estadual no Brasil entre os anos de 1998 e 2018. Com base nos dados dos Observatório de Elites Políticas e sociais observamos as variáveis gênero, escolaridade e profissão entre os postulantes aos legislativos estaduais. Testamos duas hipóteses sobre o perfil das candidaturas e dos eleitos: popularização e profissionalização. Os dados indicam que mulheres ainda estão sub-representadas e que o nível superior completo é um atributo de candidatos e eleitos. Os nossos achados sinalizam para uma maior presença de políticos profissionais entre os eleitos, confirmando assim a noção de que estaria ocorrendo uma profissionalização da competição política. Embora o pleito de 2018 apresente resultados diferentes dos anteriores, a competição política no país está seguindo o padrão de democracias mais antigas, nas quais agentes já inseridos no campo político tendem a terem mais chances de eleição.
\end{abstract}

Palavra-chave: Recrutamento político; Profissionalização política; Elites Políticas; Legislativos Estaduais;

\begin{abstract}
The paper analyzes the evolution of the social profile of successful and unsuccessful candidates to the position of state deputy in Brazil between 1998 and 2018. Based on data from the dos Observatório de Elites Políticas e sociais we observe the variables gender, education and profession among the postulants to state assemblies. We tested two hypotheses about the profile of successful and unsuccessful candidates: popularization and professionalization. The data indicates that women are still political underrepresented and that the college degree is an attribute of successful and unsuccessful candidates. Our findings point to a greater presence of professional politicians among the elected, what confirms the notion that was taking
\end{abstract}

\footnotetext{
* Doutorando em Ciência Política na Universidade Federal do Rio Grande do Sul (UFRGS). Bacharel em Ciências Sociais pela Universidade Federal da Grande Dourados (UFGD), mestre em Ciência Política pela Universidade Federal do Paraná (UFPR) e doutorando em Ciência Política na Universidade Federal do Rio Grande do Sul (UFRGS). Editor da área de Ciência Política da Revista Paraná Eleitoral. E-mail: tiagoalexandrel@ gmail.com

** Doutorando em Ciência Política no Programa de Pós-Graduação em Ciência Política da Universidade Federal do Rio Grande do Sul. Bacharel em Ciências Sociais pela Universidade Federal do Rio Grande do Sul (UFRGS). E-mail: brunomschaefer@gmail.com
} 
place a professionalization of the political competition in Brazil. Although the 2018 election presents different results from previous ones, political competition in the country is following the pattern of older democracies, in which agents already inserted in the political field tend to have more electoral chances.

Keywords: Political recruitment; Political professionalization; Political Elites; State Assembly.

Resumen: El paper analiza la evolución del perfil social de los candidatos y elegidos para el puesto de diputado provincial en Brasil entre 1998 y 2018. Con base en datos del Observatório de Elites Políticas e sociais, observamos las variables género, educación y profesión entre los postulantes a las Asambleas Provinciales. Testamos dos hipótesis sobre el perfil de los candidatos exitosos y no exitosos: la popularización y la profesionalización. Los datos indican que las mujeres todavía aún están su representadas en la representación política provincial y que el título universitario es un atributo de los candidatos exitosos y no exitosos. Nuestros hallazgos apuntan a una mayor presencia de políticos profesionales entre los elegidos, lo que confirma la noción de que se estaba produciendo una profesionalización de la competición política. Si bien las elecciones de 2018 presentan resultados diferentes a las anteriores, la competición política en el país sigue el patrón de las democracias más antiguas, en las que los agentes que ya están insertos en el campo político tienden a tener más posibilidades de victoria electoral.

Palabras clave: Reclutamiento Político; Profesionalización Política; Elites Políticas; Asambleas Provinciales.

\section{INTRODUÇÃO}

Parlamentos raramente são reflexos da estrutura social em que estão inseridos (DAHL, 1997; GAXIE, 2012; BEST; COTTA, 2000; NORRIS, 1997). Existem profissões que parecem se ligar a política de forma "natural", como se fosse por osmose, nas palavras de Dogan (1999). Ou seja, possuem maior probabilidade de adentrar (e permanecer) ao campo político (NORRIS; LOVENDUSKI, 1997). A variável ocupação associada à representação política, em especial nos Legislativos nacionais, tem sido uma preocupação longínqua dos estudos de Ciências Sociais preocupados com a questão: “quem nos governa?" (JOIGNANT, 2009). Desde Weber [1919] (2014), ao menos, diversos pesquisadores e pesquisadoras têm se debruçado sobre a questão, buscando identificar e comparar os padrões ocupacionais da classe política ao redor do mundo.

No caso brasileiro, os legisladores do país foram objeto de estudo de diversas pesquisas (MARENCO DOS SANTOS, 1997; MESSENBERG, 2008; MARENCO DOS SANTOS; SERNA, 2007; COSTA; CODATO, 2013; RODRIGUES, 2002, 2006, 2014). Os objetivos dos trabalhos, as metodologias, conclusões e formas de classificação adotadas no tratamento dos dados variaram de acordo com os pesquisadores em questão. A despeito das diferenças metodológicas das pesquisas é possível identificar a tendência na escolha do objeto. Parte expressiva das pesquisas são sobre a Câmara Federal (RODRIGUES, 2002, 2006, 2014; MARENCO DOS SANTOS, 1997; PERISSINOTTO; MIRÍ.ADE, 2009), outras sobre o Senado 
(COSTA; CODATO, 2013; NEIVA; IZUMI, 2012, 2014). A Câmara acaba sendo estudada com maior destaque devido ao seu peso decisório no arranjo do sistema político brasileiro (PALERMO, 2000).

Nesse trabalho, o nosso objetivo foi perceber a relação entre partidos políticos, ocupações e o recrutamento de candidatos e eleitos para as Assembleias Legislativas do país. Utilizamos os dados dos candidatos e eleitos ao cargo de deputado estadual ${ }^{1}$ no Brasil entre a eleição de 1998 até 2018. O banco de dados, originalmente disponível no sítio eletrônico do Tribunal Superior Eleitoral (TSE), foi sistematizado pelo Observatório de elites políticas e sociais do Brasil, e conta com informações sobre: gênero, profissão, idade e escolaridade dos postulantes ao cargo no país. Para o ano de 2018, sistematizamos as informações a partir dos dados do TSE.

Testamos duas teses ao longo do texto. São elas: a ideia de popularização, formulada por Rodrigues (2002) e a de profissionalização, empiricamente constatada por, entre outros, Costa e Codato (2013). Essas duas teses apontam para sentidos diferentes da representação política no país. Elas foram formuladas para outro conjunto de dados e outros cargos (Deputados Federais e Senadores), e, bem por isso, buscamos testá-las empiricamente para o caso da representação política no nível legislativo estadual, de forma a expandir o escopo da análise. Nesse sentido, o objetivo do trabalho foi fazer um teste de hipóteses, conforme os trabalhos desse tipo (KING; KEOHANE; VERBA, 1994).

Os deputados estaduais foram poucos estudados por várias razões: desde o baixo poder decisório das Assembleias Legislativas (essas Casas de Leis acabam por ser ratificadoras das propostas de Governadores), até o fato de não existirem incentivos a permanência nessa posição política: ao contrário dos deputados federais, os deputados estaduais não possuem o recurso a emendas parlamentares. Mesmo por isso, o estudo desse cargo torna-se importante na medida em que esse pode servir como trampolim a conquista de novos cargos, nos diversos níveis da federação. Esse cargo é um ponto chave para carreiras políticas. Por ser mais baixo na hierarquia política, esperamos que o perfil dos eleitos seja mais "popular", pois a medida que se sobe na hierarquia política os perfis tendem a serem mais "elitizados" (GAXIE, 2012).

O trabalho está dividido em quatro seções. A primeira apresenta uma breve revisão dos trabalhos sobre recrutamento político, em específico os textos sobre as pesquisas sobre os legisladores estaduais no país. Na sequência, apresentamos o desenho da pesquisa e as hipóteses do trabalho. A terceira parte do trabalho é dedicada aos resultados da investigação. Por último, retomamos alguns dos achados do artigo e tecemos as considerações finais.

\footnotetext{
${ }^{1}$ Nos referimos a noção de deputado estadual que engloba inclusive os deputados distritais do Distrito Federal.
} 


\section{ESTUDOS SOBRE DEPUTADOS ESTADUAIS E AS HIPÓTESES DA PESQUISA}

$\mathrm{O}$ arranjo federativo do Estado brasileiro determina a representação política em três níveis: federal, estadual e municipal. As interpretações sobre a política nacional são recheadas de alusões ao aspecto regional da competição eleitoral no país. Desde estudos clássicos como os de Leal (1976), do próprio sistema partidário e suas lógicas regionais (LIMA JR, 1983), ou ainda o poder dos governadores vis-à-vis a política nacional (ABRÚCIO, 1998). Especificamente sobre o perfil dos legisladores das Assembleias Legislativas estaduais, o tema tem sido trabalhado com menor destaque pela Ciência Política brasileira, quando se comparam os estudos sobre a Câmara dos Deputados e o Senado. Em termos metodológicos, os trabalhos sobre os legislativos estaduais podem ser separados entre aqueles com uma estratégia mais próxima ao estudo de caso e aqueles nas quais uma ou mais Casa de Leis Estaduais são analisadas comparativamente.

Os estudos que focam em um legislativo estadual específico cobriram estados de todas as regiões do país. O Centro-Oeste teve o perfil dos seus legisladores estudados por Lourenço (2011) e Silveira (2009) discutindo o caso de Mato Grosso. No Mato Grosso do Sul, o trabalho de Barbosa (2014) apresenta dados o legislativo do estado e a Assembleia Legislativa do Estado de Goiás (ALEGO) foi objeto de pesquisa por Mota (2011). Já o Sul do país teve dois dos seus legislativos debatidos entre os pesquisadores da temática. O Rio Grande do Sul foi objeto de Damin e Rebello (2009), Silveira (2014), Gugliano e Orsato (2012) e Orsato (2013). Já o Paraná foi estudado por Perissinotto; Costa e Tribess (2009). Outros estudos de caso foram empreendidos por Prati $(2013,2016)$, sobre o Espírito Santo, e sobre a formação de deputados de uma região específica Pessoa Júnior (2011), ou de apenas um deputado estadual Mourão (2012). Ainda encontramos na literatura trabalhos não diretamente vinculados a problemática do recrutamento, mas que contribuem com dados sobre o perfil social dessa categoria de legisladores, que são os casos de Cyrimot (2015) que versa sobre os policiais militares no Estado de São Paulo e também Borges (2009) sobre deputados estaduais evangélicos.

O outro conjunto de trabalhos são marcados por uma estratégia comparativa. Duas ou mais Assembleias são comparadas tanto para se observar os padrões de carreira dos parlamentares, como o exposto por Corrêa (2016), ou o perfil dos eleitos no país (HORTA et al, 2014; SILVA; BORGES, 2017; ANASTASIA; CORREA; NUNES, 2012), ou ainda o aspecto da representação feminina entre os deputados estaduais (CAMPOS, 2015). Outro tipo de pesquisa realizado sobre o perfil dos eleitos para os legislativos foca em comparações em dois ou três casos. Assim, Lima (2016) compara o perfil das mulheres negras eleitas nas Assembleias de São Paulo e Bahia, mas a autora também apresenta dados sobre as outras regiões do país. Ziegman (2011) compara o perfil dos legisladores eleitos pelos estados do Paraná, São Paulo e Minas Gerais e busca vincular esse perfil com as decisões tomadas, e Sampaio (2012) compara o perfil dos eleitos do em Minas Gerais e Rio de Janeiro. 
Esses são alguns dos artigos, teses e dissertações que tratam, de uma forma ou de outra, sobre o perfil social dos legisladores estaduais no Brasil. Evidentemente, a pretensão dessa revisão de literatura não foi esgotar toda a temática, e é igualmente importante pontuar que um outro conjunto de trabalhos focam outras dimensões dos deputados estaduais como a geografia do voto (RODRIGUES; SOUSA, 2017), os valores dos legisladores (PERISSINOTTO; BRAUNERT, 2006) e o auto posicionamento dos deputados estaduais no espectro ideológico é discutido por (KINZO, 2007).

No que toca ao perfil dos parlamentares estaduais, que são o objeto desse trabalho, esses citados estudos encontram achados semelhantes ao das pesquisas sobre o Congresso Nacional. Assim, as taxas de mulheres entre os eleitos tendem a ser baixas no país inteiro, e em estados específicos como o Mato Grosso do Sul (BARBOSA, 2014). O nível superior tende a ser a regra entre os eleitos, e algumas profissões se repetem entre os representantes estaduais.

Em que se pese esse conjunto de trabalhos sobre o perfil dos eleitos ou mesmo das candidaturas, algumas das teses e interpretações sobre a classe política do país foram formuladas tendo como objeto de estudo os deputados federais (SANTOS, 2001; RODRIGUES, 2002, 2006, 2014; SIMONI JUNIOR; MUCINHATO; MINGARDI, 2016) ou sobre o Senado Federal (COSTA; CODATO, 2013). São desses estudos que retiramos as duas hipóteses que serão testadas nesse trabalho:

\section{H0: Hipótese nula}

Antes da apresentação das hipóteses do trabalho, convém notar que existe a possibilidade de não existirem padrões entre os predicados sociais dos candidatos, eleitos e as direções que a classe política possa ter. Do ponto de vista estatístico, isso significaria que as nossas variáveis não possuem uma relação entre si.

\section{H1: Estaria em marcha a popularização da classe política}

A hipótese da popularização da classe política foi formulada por Rodrigues (2006; 2014). De acordo com o autor, a partir da conquista do Executivo federal pelo Partido dos Trabalhadores (PT) em 2002, estaria ocorrendo uma mudança no perfil dos eleitos no país. No primeiro estudo, Rodrigues (2006) compara o perfil dos deputados federais eleitos em 1998 e 2002, as suas conclusões são baseadas em quatro indicadores: i) diminuição do número de empresários entre os eleitos; ii) escolaridade dos eleitos; iii) crescimento das bancadas de partidos de esquerda (PT e PCdoB) e iv) aumento no número de sindicalistas e pastores. No segundo trabalho, Rodrigues (2014) reitera o diagnóstico da mudança no recrutamento dos deputados oriundos das camadas "ricas' e sintetiza o processo como: "Se estivéssemos na Roma antiga, poderíamos dizer que houve recuo dos patrícios e avanço dos plebeus" (RODRIGUES, 2014, p.157). Dessa forma, se o autor estiver correto, os nossos dados deveriam apontar para um 
incremento no número de trabalhadores eleitos, mas em maior medida a redução do empresariado e aumento no número de profissões relativas as "camadas médias": como pastores e policiais, por exemplo. Além disso, dada a grande desigualdade social no Brasil, que impacta diretamente o acesso ao Ensino Superior, seria razoável esperar que se Rodrigues estiver certo, o efeito de um diploma seria menor ao longo do tempo.

\section{H2: Estaria em marcha a profissionalização da competição política}

Essa hipótese é retirada dos trabalhos de Perissinotto e Bolognesi (2010) e Costa e Codato (2013), principalmente. No primeiro caso, os autores se baseiam nos dados de candidatos e eleitos ao cargo de deputado federal entre 1998 e 2006, em um desenho de pesquisa bastante próximo ao nosso, enquanto no segundo caso os autores trabalham com o perfil dos senadores eleitos entre os anos de 1986 a 2010. A prosopografia realizada nesse caso é mais rica do que a de Rodrigues (2006; 2014), por levar em conta não só o perfil social (gênero, escolaridade, profissão), mas a carreia política dos parlamentares (quantidade de cargos ocupados e tempo de carreira).

De acordo com Costa e Codato, depois de observarem os resultados sobre a redução do empresariado, afirmam que: “(...) a queda de empresários (seja na Câmara, seja, em menor medida, no Senado), antes de representar a "popularização", pode representar maior controle das oportunidades por indivíduos desde muito cedo dedicados às atividades políticas" (COSTA; CODATO, 2013, p. 122). Os nossos dados não permitem chegar à trajetória dos candidatos e eleitos, pois trabalhamos com as fontes do TSE. Mas utilizamos a categoria "político" entre as profissões, como uma tentativa de se observar se esse segmento tem de fato dominado a representação nas assembleias legislativas, e tem aumentado sua participação no poder desde as eleições de 1998. Esse caminho também foi trilhado por Perissinotto e Bolognesi (2010). Os autores encontram evidências de que o acesso à Câmara dos Deputados estaria se fechando ao longo do tempo em torno dos autodeclarados políticos profissionais. Esse fato seria uma proxy de observação da institucionalização daquela Casa de Leis, afinal de contas, quanto mais profissionais, maior o recrutamento é claramente diferenciado e demarcadas são as fronteiras entre os de "dentro" e os de "fora" da Instituição. Agora, passamos a descrição da metodologia e fontes do trabalho.

\section{METODOLOGIA E FONTES}

A metodologia empregada nesse trabalho é a prosopografia (STONE, 2011). Essa metodologia é comumente utilizada nos estudos sobre elites políticas citadas acima. As dificuldades na sua utilização, tratadas no caso desse estudo, é de que essas informações foram fornecidas pelos próprios candidatos às justiças eleitorais estaduais. No caso especifico do nosso 
estudo, é a declaração de indivíduos que informaram a categoria "outros". De todo modo, esse tipo de método de trabalho significa que:

[...] a investigação das características comuns de um grupo de atores na história por meio de um estudo coletivo de suas vidas. O método empregado constituise em estabelecer um universo a ser estudado e então investigar um conjunto de questões uniformes - a respeito de nascimento e morte, casamento e família, origens sociais e posição econômica herdada, lugar de residência, educação, tamanho e origem da riqueza pessoal, ocupação, religião, experiência em cargos e assim por diante. Os vários tipos de informações sobre os indivíduos no universo são então justapostos, combinados e examinados em busca de variáveis significativas. Eles são testados com o objetivo de encontrar tanto correlações internas quanto correlações com outras formas de comportamento ou ação (STONE, 2011, p.115).

No nosso caso, buscamos observar as características sociais dos candidatos e eleitos ao cargo de deputado estadual no país. O objetivo da pesquisa foi observar os padrões de recrutamento dos deputados estaduais no Brasil entre as eleições de 1998 até 2018. A pesquisa foi desenhada a partir dos dados do TSE. Essas informações são fornecidas pelos candidatos e candidatas aos Tribunais Regionais Eleitorais dos estados e repassadas ao TSE. Os dados incluem: i) gênero; ii) profissão; iii) idade; iv) estado de nascimento; v) escolaridade; e de 2014 em diante a autodeclararão racial $^{2}$. O Observatório de elites políticas e sociais do Brasil organizou essas informações, das quais foram testadas as hipóteses do trabalho, mas recodificarmos os dados para todos os pleitos e incluímos informações acerca das eleições de 2018. Ao total foram sistematizadas as informações de 72.506 candidatos e candidatas ao posto de legislador estadual.

De saída, é importante ressaltar duas observações sobre a utilização dos dados. A primeira de ordem metodológica e a segunda conceitual. Em relação a nossa opção por utilizar tanto os dados dos candidatos e dos eleitos, podemos ampliar o teste da hipótese de que estaria ocorrendo uma popularização da classe política, pois ao observar o perfil dos postulantes foi possível observar se tanto o número de candidatos "populares" aumentou quanto analisar se a presença de ocupações de "elite" diminuiu. Isso se deve ao fato de não trabalharmos só com o perfil dos eleitos, como o fazem os pesquisadores que testaram a hipótese em outro conjunto de dados: Costa e Codato (2013) para os Senadores e Simoni Junior; Mucinhato; Mingardi (2016) para Deputados Federais e Senadores. Em relação à variável profissão, os dados do TSE são informados pelos próprios candidatos. Diante dessa fonte ou de outras, as estratégias adotadas pelos estudos de elite variam de acordo com os objetivos de cada pesquisador (CODATO; COSTA; MASSIMO, 2014). No nosso caso, optamos pela classificação de Codato; Cervi e Perissinotto (2013). Mas antes de apresentar a categorização dessa variável, observamos primeiramente as informações declaradas nas candidaturas. Ao todo, os candidatos e candidatas declararam 249 ocupações, incluindo a categoria "outros" e os que não informaram a profissão, o que resulta em 247 ocupações declaradas ao TSE. Inicialmente, realizamos uma análise de

\footnotetext{
${ }^{2}$ Os dados também incluem o patrimônio declarado dos candidatos.
} 
frequência descritiva com vista a perceber quais eram as profissões que mais foram declaradas.

Tabela 1- Profissões declaradas pelos candidatos e candidatas ao cargo de deputado estadual no Brasil (1998-2018):

\begin{tabular}{lcc}
\hline Ocupação declarada & Frequência & \% \\
\hline Outros & 10558 & 14,6 \\
Empresário & 5044 & 7,0 \\
Advogado & 4413 & 6,1 \\
Comerciante & 3518 & 4,9 \\
Servidor público estadual & 3059 & 4,2 \\
Medico & 2621 & 3,6 \\
Deputado & 2249 & 3,1 \\
Vereador & 2204 & 3,0 \\
Não informada & 1631 & 2,2 \\
Aposentado (exceto funcionário & 1439 & 2,0 \\
público) & 1409 & 1,9 \\
Administrador & 38145 & 52,6 \\
\hline Total: & &
\end{tabular}

Fonte: Observatório de elites políticas e sociais do Brasil e TSE (2018).

A tabela acima indica que a categoria outros foi a mais recorrente entre as declarações nas candidaturas com 14,6\% do total, seguida pela declaração de empresários, 7,0\% do total. Depois dessas ocupações, o banco de dados continha mais nove ocupações que em conjunto representam 52,6\% do total. Por último, as demais ocupações autodeclaradas tiveram frequência percentual menor no total da população. Como objetivo do trabalho é realizar o teste de duas teses, optamos pela categorização das ocupações inspirada no trabalho de Codato; Cervi e Perissinotto (2013), que distribuíram as ocupações dos candidatos as prefeituras em $2012 \mathrm{em} \mathrm{dez}$ categorias, que são elas já com o número de caso e porcentagem do nosso banco de dados. Em nosso caso, expandimos as categorias para 15 ao total, conforme exposto na tabela 2: 
Tabela 2 - Profissão dos candidatos e eleitos ao cargo de deputado estadual (1998-2018):

\begin{tabular}{lll}
\hline Ocupação & \% & \% Cumulativo \\
\hline Empresários & 14,7 & 14,7 \\
Outras & 14,6 & 29,3 \\
Trabalhadores & 13,7 & 42,9 \\
Profissões com nível & 12,8 & 55,8 \\
superior & & \\
Políticos & 7,9 & 63,7 \\
Funcionários Públicos & 7,6 & 71,3 \\
Advogados & 6,1 & 77,4 \\
Professores & 6,1 & 83,5 \\
Forças Policiais & 4,5 & 88,0 \\
Médicos & 3,6 & 91,6 \\
Aposentados & 2,7 & 94,4 \\
Sem informação & 2,2 & 96,6 \\
Estudantes & 1,8 & 98,4 \\
Donas de Casa & 1,0 & 99,4 \\
Sacerdotes &, 6 & 100,0 \\
\hline
\end{tabular}

Total

Fonte: Observatório de elites políticas e sociais do Brasil e TSE (2018).

Na categoria empresários incluímos ocupações como diretor de empresas, comerciantes e pecuaristas. Na categoria trabalhadores incluímos uma série de ocupações de remuneração média e/ou baixa que vai desde torneiro mecânico até agente administrativo e trabalhadores autônomos como corretores de imóveis. A categoria "profissões com nível superior" engloba carreiras que necessitam de um diploma de ensino superior: como agrônomo, arquiteto, cientista político e assim por diante. Esse tipo de categorização serve para tornar mais clara a análise proposta no trabalho. Quanto ao ponto da auto declaração ocupacional, ao mesmo tempo em que pode encobrir relações de interesse (o empresário que se declara economista), é útil, pois: "as classificações ocupacionais são parte das lutas específicas pelo reconhecimento e pela adesão de apoios, não podem ser desconsideradas as lógicas e razões da produção e a divulgação dos registros oficiais", conforme Bordignon (2013, p.43). Ou seja, mesmo que existam declarações falsas, essas são úteis, pois demonstram quais grupos os postulantes ao cargo querem, ou não, dizer representar.

\section{A CLASSIFICAÇÃO DOS PARTIDOS POLÍTICOS}

Os postulantes ao cargo de deputado estadual se apresentaram por 45 partidos políticos, que foram classificados no continuum esquerda x direita. Na literatura são diversas as estratégias de classificação: a auto identificação dos próprios parlamentares (RODRIGUES, 1987), autoclassificação dos parlamentares e seus correligionários (POWER; ZUCCO, 2011); análises sobre estatutos e programas de governo (TAROUCO; MADEIRA, 2013), vinculação entre origens sociais de parlamentares e organização partidária (RODRIGUES, 2002), e mesmo surveys com especialistas (TAROUCO; MADEIRA, 2015). Existe um relativo consenso sobre alguns dos 
partidos do sistema partidário, em especial para as legendas mais antigas: PT, PDT, PSDB, PMDB, PTB, PP e DEM. Já outras legendas do sistema partidário são desconhecidas até por especialistas da área, conforme apontado por Tarouco e Madeira (2015).

Além da classificação dos partidos a partir de categorias "clássicas": direita, esquerda e centro, Coppedge (1997; 1998), propôs uma classificação alternativa, situando os partidos latino americanos em dois eixos: se secular ou religioso (1), e "cor" ideológica: centro, centro-esquerda, esquerda, centro-direita, direita e personalista (2). Essa tipologia prevê até 13 possibilidades de partidos. Codato e Bolognesi (2018) utilizam os critérios de Coppedge para classificar os partidos brasileiros que competiram em pleitos nacionais de 1998 até 2014. Nos baseamos no proposto nesses critérios para classificar os partidos de nossa amostra, principalmente porque possibilita o olhar à nuances do sistema partidário brasileiro, como diferenças no interior da esquerda e no interior da direita. No caso da última, existem diferenças entre partidos que se ancoram em uma ideologia religiosa cristã, por exemplo, e outros com uma ideologia liberal na questão econômica, defendendo privatizações e liberalização do mercado. Outro ganho explicativo da proposta de Coppedge (idem) é que foi desenvolvida para o caso latino-americano, ao contrário de outras classificações baseadas nos sistemas partidários europeus. Seguindo essa argumentação, os partidos que competiram entre 1998 e 2018 foram classificados da seguinte forma:

i) Secular de Esquerda: PCB, PCO, PSOL, PSTU e PPL.

ii) Secular de Centro-Esquerda: PCdoB, PDT, PSB e PT.

iii) Secular de Centro: PMDB, PPS, PSDB, PV e REDE.

iv) Personalista: PAN, PHS, PMN, PRONA, PROS, PRP, PST, PtdoB(AVANTE), PTC, PTN(PODEMOS), SD e PMB.

v) Secular de Direita: DEM(PFL), PGT, PL, PP(PPB), PRTB, PSD, PSL, PTB e NOVO.

vi) Confessional de Direita: PEN(PATRI), PR, PRB, PSC e PSDC(DC).

Na próxima sessão tratamos das teses que foram testadas no trabalho.

\section{RESULTADOS}

As Assembleias legislativas do país variam na quantidade de cadeiras entre um mínimo de 24 até o máximo de 94. Os dados que apresentamos abaixo, refletem os resultados por bloco ideológico ao longo de seis eleições realizadas no país. A tendência é de um aumento dos seculares de esquerda durante as administrações petistas e uma redução dos seculares de centro. Os resultados de 2018 indicam casas de leis dominadas pelos seculares de direita (30,5\%), 12,3\% de personalistas e 13,3\% de confessionais de direita, o que indica maior polarização quando comparadas eleições anteriores. 
Gráfico 1- Resultados eleitorais para deputado estadual no Brasil (1998-2018)

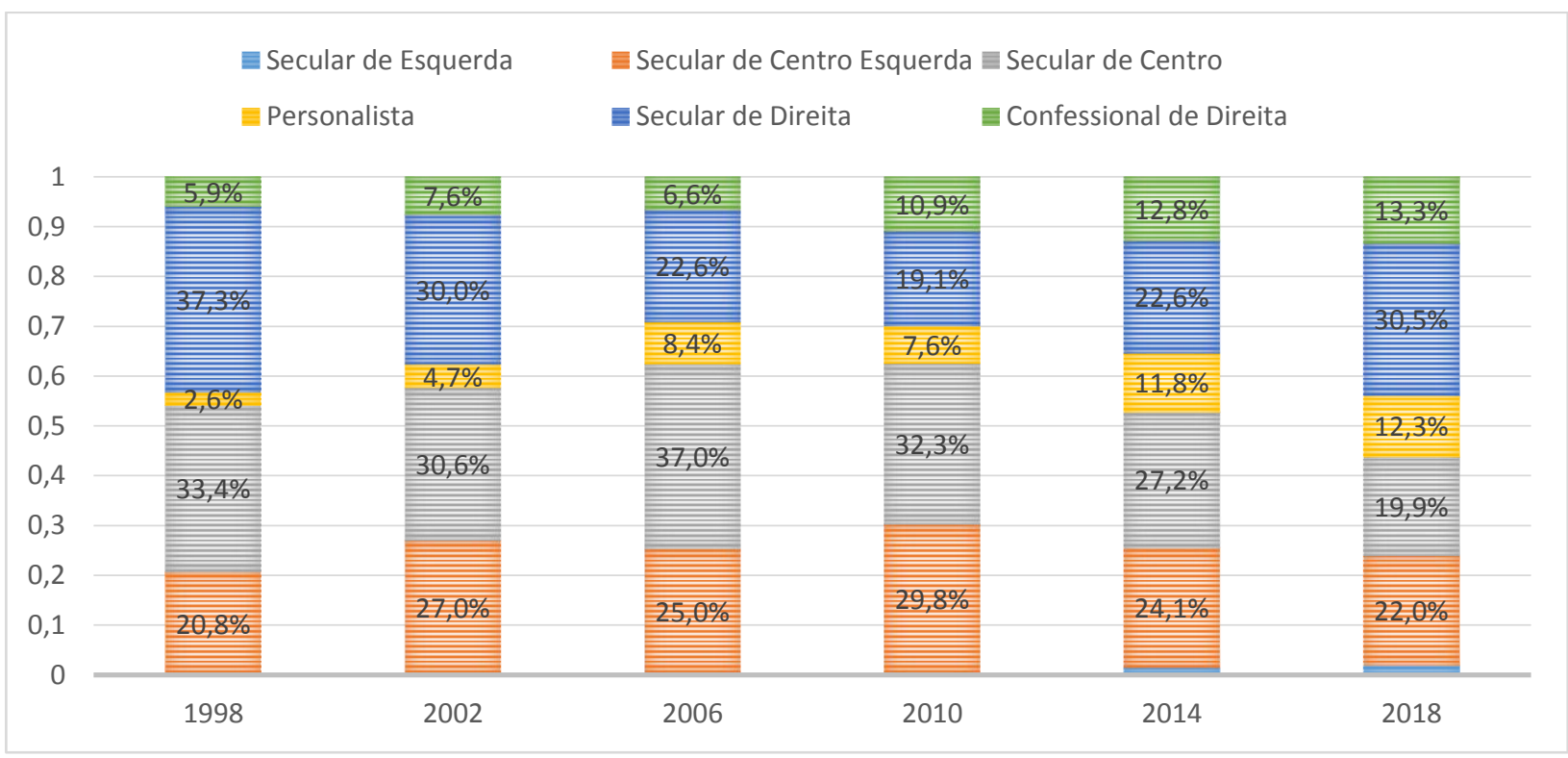

Fonte: Observatório de elites políticas e sociais do Brasil e TSE (2018).

Os dados acima mostram as evoluções dos blocos ideológicos ao longo do tempo. A relação entre o recrutamento de determinadas profissões e os blocos ideológicos já fora apresentada por Duverger (1992). No Brasil, Rodrigues (2002) formulou a hipótese de que existiria uma correspondência entre a localização dos partidos no espectro ideológico e o recrutamento dos deputados federais. A hipótese do autor é de que partidos de esquerda seriam caracterizados, não na sua totalidade, por professores, trabalhadores, "camadas médias"; enquanto a direita seria formada por empresários, diretores de empresas, "membros das camadas altas"; e o centro seria dominado por advogados, funcionários públicos e políticos profissionais.

Para verificar a proximidade entre os campos ideológicos e categorias ocupacionais realizamos o teste de Análise de Correspondência Simples (ACS). Souza; Basto e Vieira, (2010, p.2), afirmam que a ACS pode ser definida: “(...) como uma técnica de análise multivariada, adequada para dados categóricos, que permite analisar graficamente as relações existentes através da redução de dimensionalidade do conjunto de dados". Ou seja, a partir da comparação entre duas variáveis pode ser observar graus de associação, demonstrados graficamente. Nossas variáveis cobrem seis respostas de campos ideológicas e quinze respostas para categorias ocupacionais. Nas figuras 1 e 2 podemos observar que as correspondências se diferenciam entre os candidatos e entre os eleitos. Num primeiro momento, vemos que trabalhadores, por exemplo, estão mais próximos dos partidos Confessionais de Direita e Personalistas, quando considerados os candidatos. Quando considerados os eleitos, essa categoria ocupacional se mostra mais próxima dos partidos de Centro-Esquerda. Essa diferença indica que partidos confessionais de direita e personalistas tendem a concentrar os candidatos autodeclarados trabalhadores, mas os 
eleitos se concentram, conforme apontado por Rodrigues (2002), na esquerda do campo político.

Figura 1- (ACS) Relação entre bloco ideológico e profissões dos candidatos a deputados estaduais (19982018):

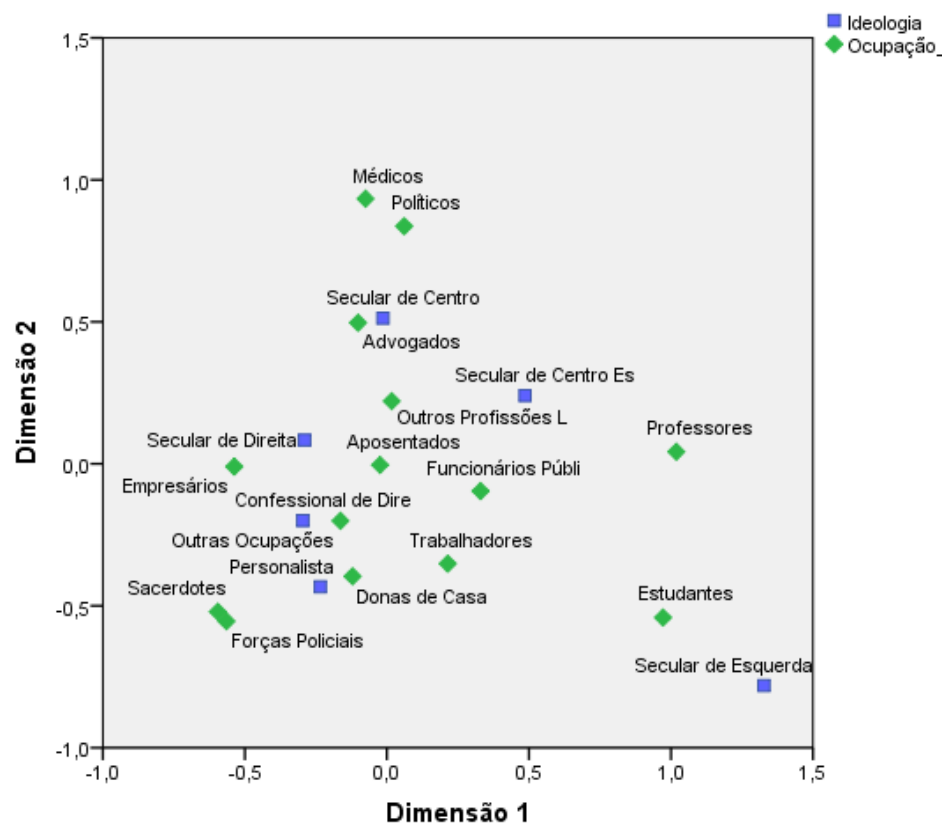

Fonte: Observatório de elites políticas e sociais do Brasil e TSE (2018).

Figura 2- (ACS) Relação entre bloco ideológico e profissões dos deputados estaduais eleitos (1998-

2018):

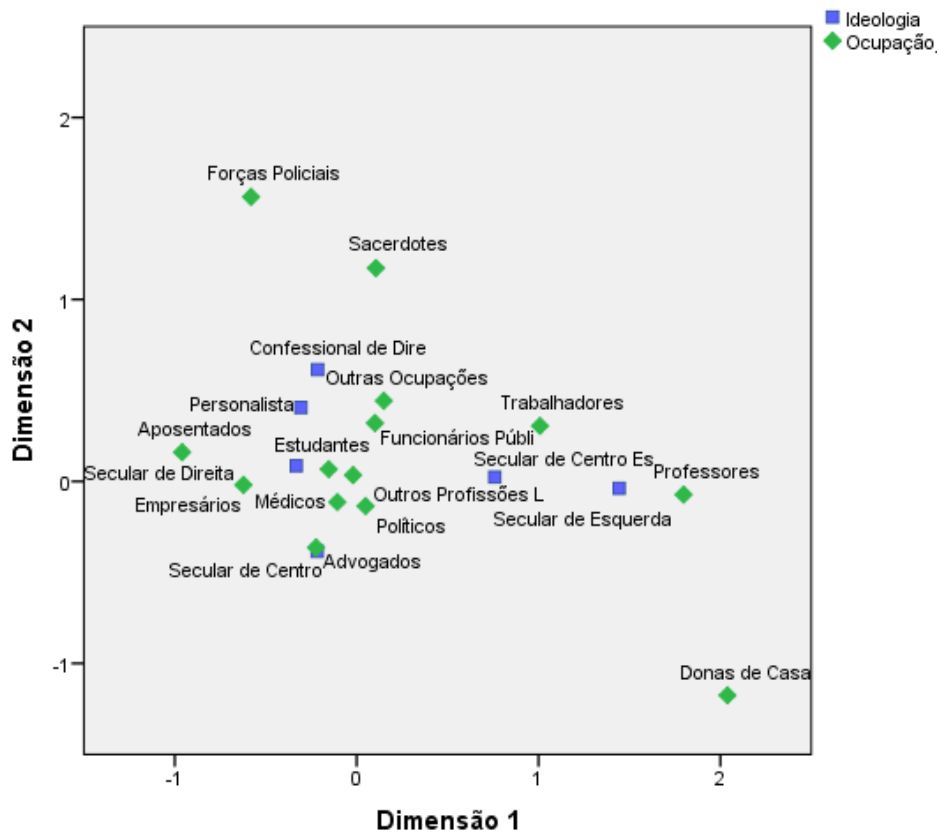

Fonte: Observatório de elites políticas e sociais do Brasil e TSE (2018). 
Os dados expostos a partir da ACS reafirmam considerações expostas em trabalhos anteriores sobre a elite política brasileira. Advogados, Médicos e Políticos estão concentrados, tanto entre candidatos quanto eleitos, nos partidos Seculares de Centro. Empresários, por sua vez, se concentram nos partidos Seculares de Direita, candidatos e eleitos, enquanto os professores se concentram nos partidos Seculares de Esquerda e Centro-Esquerda.

Os resultados da pesquisa sobre escolaridade indicam que nessas seis eleições o nível superior completo é a tendência entre os eleitos. Os nossos dados indicam que a escolarização dos eleitos tem aumentando ao longo do tempo. Se em 1998, as taxas de deputados estaduais com formação universitária, entre os eleitos era de 63,1\%, passados 20 anos desde o pleito, os escores mostram 74,5\%. Em todas as eleições observadas, apenas a de 2002 apresentou um pequeno recuo de parlamentares com formação, $62,1 \%$, todas as demais foram marcadas por acréscimos nessas cifras: 2006 (66,9\%), 2010 (69,9\%), 2014 (71,2\%). A presença de uma elite política com alguma formação universitária remonta desde os tempos do Império, conforme Carvalho (2003). No Brasil, e no mundo, elites políticas tendem a ostentar formação diplomas universitários (UNZUÉ, 2012; NORRIS; LOVENDUSKI, 1997; IZUMI; NEIVA, 2012), entre outros. Algumas formações tendem a ser predominantes entre as elites políticas, como os bacharéis em direito (ADORNO, 1988), ou mesmo os diplomas de economia. As explicações para o fenômeno, se devem pelo fato de indivíduos com formação universitária poderem utilizar esse capital social para o mundo político (NORRIS; LOVENDUSKI, 1997).

No que toca ao gênero dos eleitos, os nossos achados revelam que o número de candidatas mulheres tem aumentando ao longo do tempo, mas isso não significou um aumento no número de eleitas. Os dados do gráfico 2, apresentam as porcentagens das candidaturas femininas, o pleito de 2018 apresenta $33,2 \%$ de candidaturas e $14,8 \%$ de eleitas.

Gráfico 2- Porcentagem de mulheres candidatas e eleitas para deputado estadual (1998-2018)

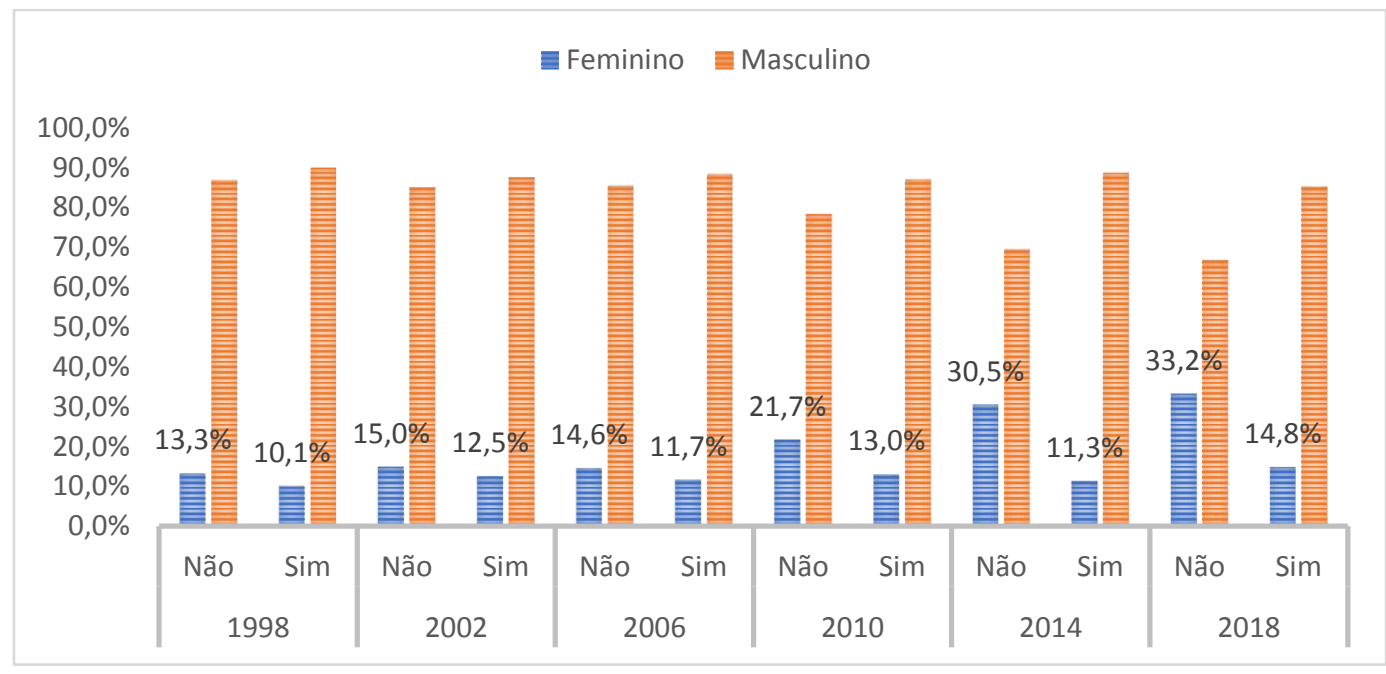

Fonte: Observatório de elites políticas e sociais do Brasil e TSE (2018). 
Os dados do gráfico acima revelam a literatura sobre sub-representação feminina pontuada pela literatura Araújo (2005), Norris (2013), Alves; Pinto e Jordão (2012). Mesmo que as últimas eleições tenham sido caracterizadas por um aumento no número de candidatas, o que pode ser explicado pelas mudanças na legislação do país, mulheres ainda se elegem menos do que homens, as cifras de 2018 de eleitas diferem pouco das encontradas em 1998. A representação feminina nos legislativos estaduais já fora objeto de estudo de Campos (2015), Lima (2016), Silveira (2014). Os fatores explicativos para a baixa presença de mulheres entre os eleitos elencados na literatura variam desde o investimento que os partidos fazem nessas candidaturas, as próprias regras eleitorais e mesmo o machismo encontrado no campo político do país.

Por fim, antes do nosso teste de hipótese, observamos a profissão dos candidatos e eleitos. Profissões como advogado, professores, políticos e funcionários públicos, estão entre algumas daquelas que a literatura de elites políticas coloca como as com mais chances de adentrar ao parlamento (NORRIS; LOVENDUSKI, 1997; DOGAN, 1999). Especificamente no Brasil, algumas profissões foram analisadas mais detidamente: empresários (COSTA; COSTA; NUNES, 2014), funcionários públicos (CODATO; FERREIRA; COSTA, 2015), advogados (BARMAN; BARMAN, 1976), policiais (BERLATTO; CODATO; BOLOGNESI, 2016), entre outras. Os resultados dos eleitos, mostram que cinco categorias ocupacionais do nosso banco de dados representam 76,9\% do total: políticos profissionais (36,7\%); profissões com nível superior (12,6\%); empresários (12,2\%); advogados (8,2\%); médicos (7,3\%). Na prática, esses resultados confirmam o que os trabalhos de elites políticas demonstram: profissões com mais tempo para se lançar à política, com habilidades que podem ser convertidas para o campo político, oratória, entre outras, são recursos que favorecem a vitória eleitoral. Representam recursos, ou capitais, adquiridos socialmente que são reconvertidos na disputa política. No mesmo sentido, os parlamentos estaduais também estão fechados para as profissões que categorizamos como "trabalhadores", essa categoria, elegeu apenas 3,3\% do total analisado ao longo das eleições.

Se, ao longo do tempo percebemos que o nível superior completo tem sido a regra entre os eleitos (mais de 70\%), que mulheres, mesmo sendo mais de $50 \%$ da população, estão presentes em menos de $20 \%$ dos eleitos, quais são as variáveis que têm mais impacto para a chegada ao cargo de deputado estadual? Em termos teóricos, os estudos sobre recrutamento lidam com a dificuldade de onde começar a análise do fenômeno, dado que o mesmo pode se iniciar mesmo na infância (CZUDNOWSKI, 1975), e é influenciado por fatores mais amplos, como as regras eleitorais e o sistema político (NORRIS, 1997). A análise das candidaturas se apresenta como uma saída possível para uma observação mais acurada do fenômeno do recrutamento político. Alguns dos trabalhos que se dedicam a esse tipo de abordagem, focam os deputados federais (PERISSINOTTO; BOLOGNESI, 2010) e os prefeitos (CODATO; CERVI; PERISSINOTTO, 2013). As vantagens desse tipo de análise é que podemos avaliar o peso das variáveis no sucesso eleitoral, e no nosso caso, ampliar o teste de hipóteses. Observando, por exemplo, se o recuo de 
uma determinada categoria de eleitos é resultado de uma diminuição no número de candidaturas.

\subsection{Para onde vai a representação política?}

O nosso recorte temporal abrangeu seis eleições. Essas eleições foram marcadas por contextos econômicos, sociais e políticos distintos. Enquanto a eleição de 2002 é um dos marcos para a proposição teórica de Rodrigues (2006), os resultados de 2018 revelaram a ascensão da extrema direita brasileira representada por Jair Bolsonaro (PSL) (KRAUSE et al, 2019). Como o objetivo do nosso trabalho é realizar testes de hipóteses, e assim contribuir com a refutação, comprovação ou reformulação dessas proposições, como determinados desenhos de pesquisa social têm (KING; KEOHANE; VERBA, 1994, p.16).

Transformamos as características sociais dos candidatos e eleitos em variáveis dummy com vistas a realização de uma regressão logística na variável depende ser eleito ou não. Assim, com essas variáveis categorizadas, buscamos testar as duas hipóteses anunciadas, bem como observar outros fatores do perfil social dos postulantes ao cargo. Assim, realizamos a seguinte operacionalização de variáveis preditoras para que um candidato à deputado estadual seja eleito:

Políticos: Colocamos aqueles candidatos que haviam declarado exercer algum cargo público. Mesmo que com essa variável não sabíamos o tempo de carreira destes indivíduos, esperamos que se a hipótese de Costa e Codato (2013) estiver correta, essa categoria vem aumentando sua chance de adentrar nos parlamentos estaduais.

Empresários: Dividimos as profissões entre aqueles que eram empresários e os que não eram do mundo dos negócios. A suposição aqui é de que essas categorias estariam perdendo espaço nos legislativos estaduais, conforme a hipótese de Rodrigues (2006; 2014). No mesmo sentido, esperamos que a variável trabalhador e sacerdote obtenham resultados maiores ao longo do tempo.

Forças policiais: Essa é uma variável conjuntural. Em que se pese a existência de análises sobre essas categorias na elite política (BERLATTO, CODATO; BOLOGNESI, 2016), buscamos observar se o pleito de 2018 apresentou maiores probabilidades desse segmento ser eleito. Dado o caráter do presidente eleito ter mobilizado o background militar para sua eleição, esperamos que candidatos com o mesmo perfil tenham utilizado a mesma estratégia.

Gênero: Com essa variável buscamos testar as chances de homens serem eleitos ao longo do tempo. Dada a conhecida literatura que versa sobre a temática e igualmente dos trabalhos sobre deputadas estaduais (LIMA, 2016; LOURENÇO, 2011), esperamos que os resultados indicassem mais probabilidades de homens do que mulheres entre os eleitos. No entanto, esse efeito pode diminuir ou aumentar ao longo do tempo.

Ensino superior: Separamos os que possuíam formação universitária e os que não detinham. A suposição, é de que aqueles que possuem diplomas universitários têm mais chances de serem eleitos dos que não têm. No entanto, caso esteja em "marcha" a popularização do acesso 
aos Parlamentos estaduais, o efeito do ensino superior diminuiria ao longo do tempo.

Direita Secular e Confessional: Essa hipótese se refere ao trabalho de Bolognesi e Codato (2018). A suposição é de que partidos "tradicionais" de direita estariam perdendo espaço para outras legendas, entre elas a Direita Confessional.

Advogado e Médico: Estas categorias ocupacionais historicamente foram sobre representadas na política brasileira. Desde o Império, conformo apontado por Carvalho (2003), os advogados constituíam a elite política brasileira - tanto eleita quanto indicada a posições de poder. A medicina constitui uma profissão de prestígio social no Brasil, sendo tal prestígio convertido politicamente para a disputa eleitoral. Conforme aponta Coradini (2006), no entanto, podem existir diferenças significativas entre o "ser médico" quando da competição eleitoral. Se de um lado existem os médicos que dizem representar uma medicina social, ou se utilizam do exercício profissional para determinadas causas sociais, de outro lado podem existir interesses corporativos ou privados, como dos médicos donos de clínicas e hospitais. Essa diferença, significativa no exercício do mandato, aqui não é considerada, pois buscamos analisar os candidatos que "chegam lá" e não como exercem seu poder e sua representação. Deste modo, o que nos interessa é observar o peso estatístico da categoria ocupacional médico na disputa eleitoral.

Idade: Consideramos como variável preditiva da eleição a idade dos candidatos. Tal como Perissinotto e Bolognesi (2010), operacionalizamos essa variável a partir de um corte arbitrário: candidatos com mais de 40 anos foram classificados na categoria sim. Esperamos que, ao contrário das eleições para o Senado e Câmara dos Deputados, a idade mais avançada não seja um fator significante para a eleição de deputados estaduais, dado que esse cargo tende a ser, para muitos, o início da carreira política.

A tabela 3 apresenta os achados dos nossos testes estatísticos. De saída, observamos que a hipótese nula é rejeitada, pois é possível observar a relação entre determinadas características sociais e o fato de ser eleito. Para não poluirmos a apresentação dos resultados com muitas informações, apenas destacamos na tabela 3, os valores de razão de chances $(\operatorname{Exp}(B))$. Esses valores indicam a probabilidade de um membro da resposta sim de uma categoria ser eleito. Por exemplo, qual a chance de um candidato autodeclarado médico vir a ser eleito em alguma das eleições analisadas.

Em primeiro lugar, podemos observar que praticamente todos os valores são significativos estatisticamente. Em segundo lugar, podemos observar as direções da representação política ao nível legislativo estadual. De saída, os dados confirmam a hipótese da profissionalização política, apresentada por, entre outros, Costa e Codato (2013). Os Exp(B), da categoria político revelam que essa categoria, mesmo em 1998 já apresentava mais probabilidades de ser eleito (6 vezes mais chances do que os não políticos). A tendência que se segue nos pleitos seguinte, é um aumento dessas cifras, chegando quase ao triplo em 2018 (17,069 mais chances). 
Esses dados são significativos sobre o funcionamento da competição política no país, pois aqueles que já faziam parte de alguma organização partidária antes do pleito, possuem mais chances de serem eleitos, mesmo em 2018, quando o debate foi marcado por uma negação da política. Ou seja, ao longo do tempo, o efeito só tende a aumentar.

Os resultados mostram também que a representação política não tem se popularizado no país. Variáveis como ser homem, ter nível superior completo, ocupar posições de prestígio como médico e empresário, ainda explicam o sucesso eleitoral, enquanto trabalhadores permanecem com poucas chances de adentrar aos parlamentos estaduais. No caso de médicos e empresários, os resultados são significantes estatisticamente em todos os pleitos analisados. Inclusive aumentado os coeficientes ao longo do tempo. Possuir diploma do ensino superior garantiu, em média 59,43\% mais chances de vitória ao longo dos pleitos analisados, sendo o ápice em 2010. O fato de ser homem apenas não foi significante estatisticamente nos pleitos de $2002 \mathrm{e}$ 2006. Nesse sentido, a hipótese da popularização não tem sustentação nos nossos dados, em que se pese que a categoria Sacerdotes tenha tido mais chances de ser eleita em metade das eleições analisadas. No ano de 2014, membros dessa categoria tiveram quatro chances mais de serem eleitos. Esse resultado, no entanto, deve ser visto com parcimônia, dado que, como demonstrado anteriormente, poucos são os sacerdotes que se lançam candidatos.

O pleito de 2018 demarcou maior acesso dos policiais ao campo político. Profissionais dessa categoria tiveram duas vezes mais chances de serem eleitos do que os não-policiais. Esse resultado demonstra que a vitória eleitoral é marcada por variáveis conjunturais, afinal de contas, em nenhum momento anterior policiais tiveram tantas chances de se eleger. Os partidos de direita secular sempre tiveram mais chances de eleger deputados estaduais, ao longo do tempo. Esse resultado, no entanto, deve ser visto com parcimônia, dado que o PSL, partido do presidente eleito, está classificado nesse campo ideológico. Logo, os coeficientes podem representar não necessariamente um fortalecimento de partidos tradicionais de direita como DEM e PP, mas sim a troca de guarda desse campo, com a chegada de organizações como NOVO e o próprio PSL.

Tabela 3- Variáveis explicativas do sucesso eleitoral dos deputados estaduais (1998-2018)

\begin{tabular}{lcccccc}
\hline & 1998 & 2002 & 2006 & 2010 & 2014 & 2018 \\
\hline Variáveis Preditoras & Exp (B) & Exp (B) & Exp (B) & Exp (B) & Exp (B) & Exp (B) \\
\hline Político & $6,807 * * *$ & $7,893 * * *$ & $11,059 * * *$ & $14,779 * * *$ & $14,074 * * *$ & $17,069 * * *$ \\
Médico & $1,779 * * *$ & $1,762 * * *$ & $2,284 * * *$ & $1,676 * *$ & $3,394 * * *$ & $5,548 * * *$ \\
Advogado & 1,190 & 1,160 & $1,499 * *$ & $1,467 * *$ & $2,379 * * *$ & $1,923 * * *$ \\
Empresário & $1,683 * * *$ & $1,652 * * *$ & $1,742 * * *$ & $1,741 * * *$ & $1,896 * * *$ & $1,877 * * *$ \\
Sacerdote & $3,575 * * *$ & $2,482 * * *$ & 1,318 & 2,529 & $4,059 * * *$ & 1,441 \\
Força Policial &, $595 *$ &, $291 * * *$ &, $469 *$ &, $512 *$ &, $423 * *$ & $2,064 * * *$ \\
Trabalhador &, $617 * *$ &, $602 * *$ &, $406 * * *$ &, 727 &, $505 * * *$ &, $332 * * *$ \\
Homem & $1,271 *$ & 1,170 & $1,267 *$ & $1,591 * * *$ & $2,348 * * *$ & $1,837 * * *$
\end{tabular}




\begin{tabular}{lcccccc} 
Idade &, 913 &, 989 & $1,193^{*}$ & 1,146 & 1,139 &, $738^{* * *}$ \\
Ensino Superior & $1,403^{* * *}$ & $1,577^{* * *}$ & $1,534^{* * *}$ & $1,715^{* * *}$ & $1,638^{* * *}$ & $1,699^{* * *}$ \\
Direita Secular & $1,607 * * *$ & $1,250^{* *}$ & $1,319^{* * *}$ &, 906 & $1,257^{* * *}$ & $1,669^{* * *}$ \\
Direita Confessional &, $649 * *$ &, $763^{*}$ &, $654^{* *}$ &, $773^{*}$ &, 891 & 1,043 \\
Constante &, 033 &, 025 &, 015 &, 010 &, 006 &, 007 \\
Cox e Snell R & 0,55 & 0,68 & 0,101 & 0,114 & 0,108 & 0,113 \\
\hline
\end{tabular}

$* \mathrm{p}<0,050 ; * * \mathrm{p}<0,005 ; * * * \mathrm{p}<0,001$

Fonte: Observatório de elites políticas e sociais do Brasil e TSE (2018).

A tese de profissionalização do campo político, como pontuada pelos autores anteriormente citados, encontra reforço nos resultados encontrados. Os candidatos que ocupavam alguma posição eletiva no momento dos pleitos possuem sempre maiores chances de se eleger. Esses valores só aumentam ao longo dos anos, passando de seis vezes mais chance até dezessete vezes em 2018. Ou seja, mesmo que os níveis de reeleição tenham sido baixos em 2018, principalmente quando observados os dados da Câmara dos Deputados e Senado, os resultados indicam que não houve uma "renovação política" significativa como alardeado por determinados analistas políticos ${ }^{3}$. A título de ilustração, como podemos observar no gráfico 3, 46,1\% dos candidatos eleitos no pleito de 2018 eram políticos. Esse resultado só não foi maior do que as eleições de 2010 e 2014, o que reforça a tese de profissionalização da classe política brasileira, também ao nível do Legislativo Estadual.

Gráfico 3- Porcentagens de candidatos “políticos” eleitos deputado estadual no Brasil (1998-2018):

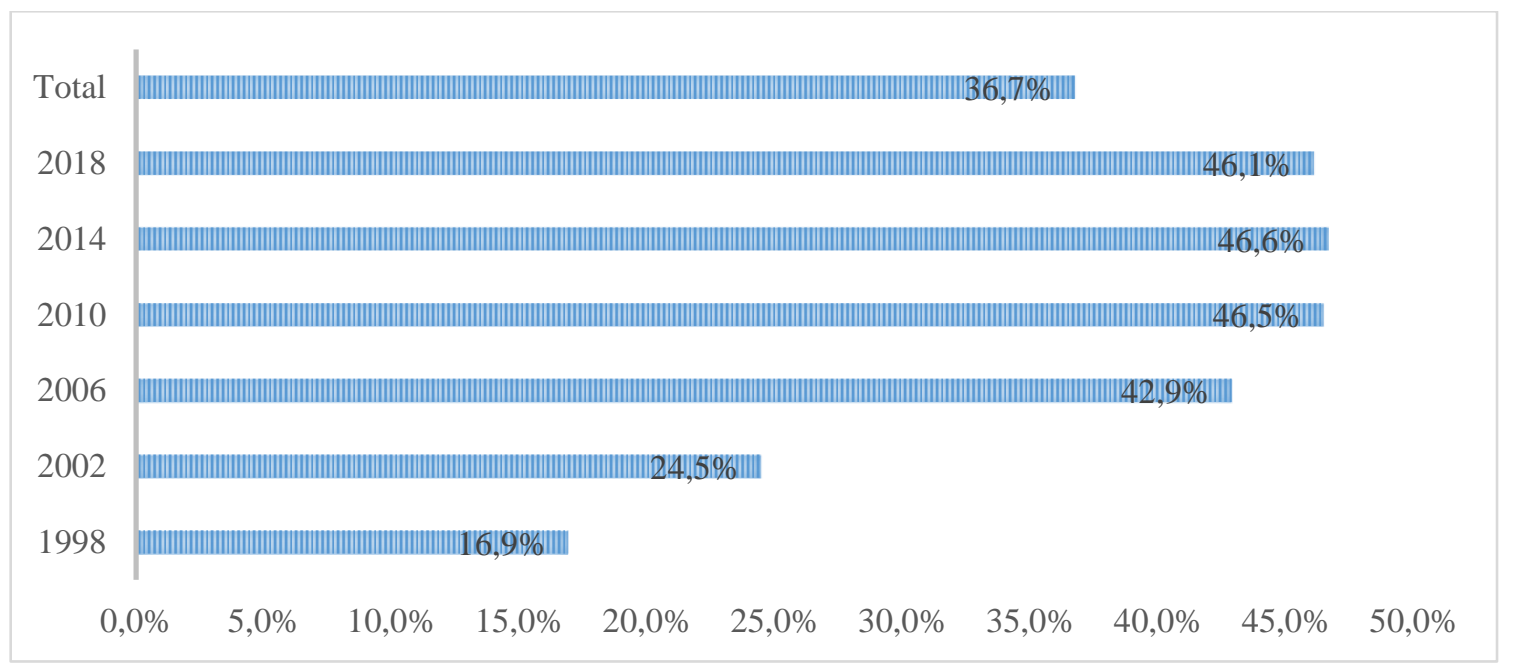

Fonte: Observatório de elites políticas e sociais do Brasil e TSE (2018).

Os resultados do teste de regressão logística possibilitam também comparar os valores das razões de chances com outros trabalhos sobre o acesso ao campo político em nível federal

\footnotetext{
${ }^{3}$ https://www.institutoliberal.org.br/blog/outubro-de-2018-a-vitoria-da-renovacao-politica-no-brasil/, acesso em 29 de julho de 2019.
} 
(deputados federais). O trabalho de Perissinotto e Bolognesi (2010), realizou o mesmo teste para observar razões de chance dos candidatos que "chegam lá" para as eleições de 1998, 2002 e 2006. Os resultados encontrados pelos autores reforçam nossos achados: os políticos profissionais tendem a ter sempre mais chances do que os não-políticos na empreitada de se eleger, sendo que essa chance - medida estatisticamente - tem aumentado ao longo do tempo. A chegada do PT ao poder, conforme apontado por Rodrigues (2014) não alterou de forma significativa esse panorama. Ao contrário de Perissinotto e Bolognesi (2010), porém, encontramos menor efeito de chance nas eleições de políticos em 2002. Para os autores, os coeficientes dobram de 1998 (6,628) para 2002 (12,074). Em nosso caso há uma mudança muito mais sútil, o que pode indicar, entre outras coisas, que o efeito da profissionalização é distinto quando se comparam diferentes Casas de Leis.

\section{CONSIDERAÇÕES FINAIS}

O objetivo do trabalho foi realizar um teste de hipóteses em um outo conjunto de dados. As hipóteses que foram formuladas para os cargos de deputado federal (RODRIGUES, 2006; 2014) ou senadores (COSTA; CODATO, 2013), foram aplicadas aos candidatos e eleitos para o cargo de deputado estadual no país. Os nossos achados, permitiram confirmar a hipótese da profissionalização política (COSTA; CODATO, 2013). Esperávamos que a popularização seria mais significativa entre os deputados estaduais, dado se tratar de um cargo mais baixo na hierarquia política.

Ao observamos candidatos e eleitos, podemos observar que variáveis como ser homem, ter nível superior completo, ser do mundo dos negócios, ou ser médico ainda exercem poder explicativo para o sucesso eleitoral. Em que se pese isso, as eleições de 2018 marcaram um incremento nas chances de sucesso da categoria "força policial", o que indica que o recrutamento também é influenciado por fatores conjunturais.

Em termos teóricos, os nossos achados mostram que a representação política no país não caminha para um maior incremento de camadas como "trabalhadores". O campo político, tende a ser dominado por profissionais já inseridos nele. Mesmo que democracias representativas nem sempre sejam um reflexo da estrutura social que estão inseridas como já afirmaram Dahl (1997), Gaxie (2012) e Dogan (1999), os nossos resultados que o fenômeno encontrado por Costa e Codato (2013) se repete em outros níveis da representação política.

Embora outras variáveis ainda precisem ser incorporadas a explicação, como: o financiamento das candidaturas, o patrimônio dos candidatos, as particularidades de cada unidade da federação, os nossos achados foram elucidativos da competição política no país. Se Putnam (1976) estiver correto, e as mudanças no perfil das elites políticas servirem como indicativos de possíveis mudanças na sociedade, esses nossos dados significam que o campo político tem se separando, ficando "autônomo", a representação política está nas mãos daqueles já inseridos no 
jogo da representação política. No entanto, isso não significa um monopólio desses agentes até porque fatores conjunturais podem explicar o processo de seleção de elites como vimos no pleito de 2018, no qual policiais se transformaram em candidaturas vitoriosas.

\section{REFERÊNCIAS}

ABRUCIO, Fernando Luiz. Os Barões da Federação: O Poder dos Governadores no Brasil PósAutoritário. São Paulo: EDUSP, 1998.

ADORNO, Sérgio. Os Aprendizes do Poder. Rio de Janeiro: Paz e Terra, 1988.

ALVES, José Eustáquio Diniz; PINTO, Céli Regina Jardim; JORDÃO, Fátima (org.). As mulheres nas eleições 2010. 1. ed. São Paulo: ABCP/SPM, 2012.

ANASTASIA, Fátima; CORREA, Izabela; NUNES, Felipe. Caminhos, Veredas e Atalhos: Legislativos Estaduais e Trajetórias Políticas. In: MENEGHELLO, Rachel. (org.). O Legislativo Brasileiro: Funcionamento, composição e opinião Pública. 1. ed. Brasilia: Senado Federal, Secretaria Especial de Comunicação Social, 2012. p. 95-122.

ARAUJO, Clara. Partidos políticos e gênero: mediações nas rotas de ingresso das mulheres na representação política. Rev. Sociol. Polit., Curitiba, n. 24, p. 193-215, jun, 2005.

BARBOSA, Tiago Alexandre Leme. Dirigentes partidários e parlamentares do PMDB no Mato Grosso do Sul (1980-2010): uma análise da origem social dos membros da Comissão Executiva, Deputados Estaduais e Federais eleitos no Estado. Dissertação (Mestrado em Ciência Política) - Setor de Ciências Humanas, Universidade Federal do Paraná, Curitiba, 2014.

BARMAN, Roderick; BARMAN, Jean. The Role of the Law Graduate in the Political Elite of Imperial Brazil. Journal of Interamerican Studies and World Affairs, New York, v. 18, n. 4, p. 423-450, 1976.

BERLATTO, Fábia; CODATO, Adriano. Candidatos e eleitos, eleições para deputados estaduais, Brasil, 1998-2014 (Banco de dados). Curitiba: Universidade Federal do Paraná (UFPR). In: Observatório de Elites Políticas e Sociais do Brasil, 2016.

BERLATTO, Fábia; CODATO, Adriano; BOLOGNESI, Bruno. Da polícia à política: explicando o perfil dos candidatos das Forças Repressivas de Estado à Câmara dos Deputados. Revista Brasileira de Ciência Política, Brasília, n. 21, p. 77-120, 2016.

BEST, Heinrich; COTTA, Maurizio. Parliamentary representatives in Europe: Legislative recruitment and careers in eleven european countries. Oxford: Oxford University Press, 2000.

BORDIGNON, Rodrigo da Rosa. Candidatos e eleitos: recrutamento e chances de sucesso nas eleições de 1998 e 2010. Paraná Eleitoral: revista brasileira de direito eleitoral e ciência política, v. 2, n. 1, 2013.

BORGES, Tiago Daher Padovezi. Identidade política evangélica e os deputados estaduais brasileiros. Perspectivas: Revista de Ciências Sociais, Araraquara, n. 35, p. 149-171, 2009.

CAMPOS, Camila Goulart. Quebrando Barreiras: uma análise descritiva das carreiras políticas das deputadas eleitas para Assembleias Legislativas/Distrital do Brasil nas eleições de 2010. Dissertação (Mestrado em Ciência Política) - Instituto de Filosofia, Sociologia e Política, Universidade Federal de Pelotas, Pelotas, 2015. 
CARVAlHO, José Murilo. A construção da ordem: a elite política imperial; Teatro de sombras: a política imperial. Editora Record, 2003.

CODATO, Adriano; BOLOGNESI, Bruno. Sociologia política dos políticos do Brasil: um estudo da competição eleitoral sob o regime da Constituição de 88. In: BUARQUE DE HOLLANDA, Cristina; VEIGA, Luciana Fernandes; AMARAL, Oswaldo E. (org.). A Constituição de 88: trinta anos depois. 1. ed. Curitiba: Ed. UFPR, 2018. p. 357-388.

CODATO, Adriano; CERVI, Emerson Urizzi; PERISSINOTTO, Renato. Quem se elege prefeito no Brasil? Condicionantes do sucesso eleitoral em 2012. Cadernos Adenauer, São Paulo, v. 14, n. 2, p. 61-84, 2013.

CODATO, Adriano; COSTA, Luiz Domingos; MASSIMO, Lucas. Classificando ocupações prévias à entrada na política: uma discussão metodológica e um teste empírico. Opin. Publica, Campinas, v. 20, n. 3, p. 346-362, dez. 2014.

CODATO, Adriano; FERREIRA, Ana Paula Lopes; COSTA, Luiz Domingos. Do serviço público à Câmara dos Deputados: os parlamentares originários do funcionalismo público no Brasil. Revista do Serviço Público, Brasília, v. 66, p. 605-626, 2015.

COPPEDGE, Michael. The dynamic diversity of Latin American party systems. Party Politics, Thousand Oaks, v. 4, n. 4, p. 547-568, 1998.

COPPEDGE, Michael. A classification of Latin American political parties, Kellog Institute, Notre Dame, n. 244, 1997.

CORADINI, Odaci Luiz. Representação profissional e elites políticas no Brasil no período recente. Política \& Sociedade, Florianópolis, v. 5, n. 9, p. 123-161, out. 2006.

CORRÊA, Filipe Souza. O que fazer para sobreviver politicamente? Padrões de carreira dos deputados estaduais no Brasil. 2016. Tese (Doutorado em Ciência Política) - Faculdade de Filosofia e Ciências Humanas, Universidade Federal de Minas Gerais, Belo Horizonte, 2016.

COSTA, Luiz Domingos; CODATO, Adriano. A profissionalização ou popularização da classe política: um perfil dos senadores da República. In: MARENCO, André (org.). Os Eleitos: representação e carreiras políticas em democracias. 1. ed. Porto Alegre: UFRGS, 2013. p. 107134.

COSTA, Paulo Roberto Neves; COSTA, Luiz Domingos; NUNES, Wellington. Os senadoresempresários: recrutamento, carreira e partidos políticos dos empresários no Senado brasileiro (1986-2010). Rev. Bras. Ciênc. Polít., Brasília, n. 14, p. 227-253, ago. 2014.

CYMROT, Danilo. Polícia Militante: deputados policiais militares na Assembleia Legislativa do Estado de São Paulo (1999-2011). 2015. Tese (Doutorado em Direito Penal), - Faculdade de Direito, Universidade de São Paulo, São Paulo, 2015.

CZUDNOWSKI, M. M. Political Recruitment. In: GREENSTEIN, F. I.; POLSBY, N. W. (ed.). Handbook of Political Science: Micro-political Theory. v. 2. Reading: Addison-Wesley, 1975. p. $155-242$.

DAHL, Robert. Poliarquia: Participação e Oposição. São Paulo: Editora Universidade de São Paulo, 1997.

DAMIN, Cláudio Júnior; REBELLO, Maurício M. Perfil dos candidatos à Assembleia Legislativa do Estado do Rio Grande do Sul para a 52 ${ }^{\mathrm{a}}$ Legislatura (2007-2010). Estudos Legislativos, Brasília, n. 3, p. 79-106, 2009. 
DOGAN, M. Les professions propices à la carrière politique. Osmoses, filières et viviers. In: OFFERLÉ, M. (ed.). La profession politique: XIXe-XXe siècles. Paris: Belin, 1999. p. 171-199.

DUVERGER, Maurice. Los Partidos Políticos. Cidade do México: Fondo de Cultura Económica, 1992.

GAXIE, Daniel. As lógicas do recrutamento político. Rev. Bras. Ciênc. Polít., Brasília, n. 8, p. 165-208, ago. 2012.

GUGLIANO, Alfredo Alejandro; ORSATO, Andréia. Women in Motion: Female Representation in the Rio Grande do Sul State Legislative Assembly. Brazilian Political Science Review, São Paulo, n. 6, p. 90-112, 2012.

HORTA, C. J. G et al. O perfil dos representantes eleitos para as assembleias legislativas no brasil. Temas de Administração Pública, Araraquara, v. 9, 2014.

JOIGNANT, Alfredo. El estudio de las élites: un estado del arte. Serie de Políticas Públicas UDP, Santiago, n. 1, p. 1-13, 2009.

KING, Garry; KEOHANE, Robert; VERBA, Sidney. Designing social inquiry: scientific inference in qualitative research. Princeton: Princeton University Press, 1994.

KINZO, M. G. Partidos, deputados estaduais e dimensão ideológica. In: KINZO, M. G.; BRAGA, M. do S. (org). Eleitores e representação política na democracia brasileira. São Paulo: Humanitas, 2007.

KRAUSE, S. et al. Die brasilianische Präsidentschaftswahl 2018: Ein neues Paradigma der Finanzierung, Anti-Politik und Soziale Netzwerke. Zeitschrift für Parteienwissenschaft, v. 25, p. 94-110, 2019.

LEAL, Victor Nunes. Coronelismo, enxada e voto: O município e o regime representativo no Brasil. São Paulo: Editora Alfa-Omega, 1976.

LIMA JR., Olavo Brasil. Os partidos políticos brasileiros: a experiência federal e regional: 1945-1964. Rio de Janeiro, Graal. 1983.

LIMA, Milena Guesso Leão de. A inserção das mulheres negras no mundo político eleitoral: uma análise sobre a sua representativade nas Assembleias Legislativas dos estados da Bahia e São Paulo. 2015. Dissertação (Mestrado em Mudança Social e Participação Política) - Escola de Artes, Ciências e Humanidades, Universidade de São Paulo, São Paulo, 2016.

LOURENÇO, Alexandra. O recrutamento das elites políticas no Brasil: o caso de Mato Grosso, 1945-2007. 2011. Tese (Doutorado em Ciência Política) - Faculade de Ciências Sociais e Humanas, Universidade Nova de Lisboa, Lisboa, 2011.

MARENCO DOS SANTOS, André. Nas fronteiras do campo político. Raposas e outsiders no congresso nacional. Revista Brasileira de Ciências Sociais, São Paulo, v. 12, n. 33, p. 87-101, fev. 1997.

MARENCO DOS SANTOS, André; SERNA, Miguel. Por que carreiras políticas na esquerda e na direita não são iguais? Recrutamento legislativo em Brasil, Chile e Uruguai. Revista Brasileira de Ciências Sociais, São Paulo, v. 22, n. 64, p. 93-113, jun. 2007.

MESSENBERG, Débora. A elite parlamentar brasileira: um recorte sociocultural. Rev. Sociol. Polit., Curitiba, v. 16, n. 30, p. 17-28, jun. 2008. 
MOTA, Regys Rodriges da. Mudanças e continuidades na elite parlamentar de Goiás: 19822010. 2011. Dissertação (Mestrado em Sociologia) - Faculdade de Ciências Sociais, Universidade Federal de Goiás, Goiânia, 2011.

MOURÃO, Pedro Jorge Chaves. A socioanálise da formação de um deputado estadual: o caso de Tomás Figueiredo Filho. 2012. Dissertação (Mestrado em Sociologia) - Departamento de Ciências Sociais, Universidade Federal do Ceará, Fortaleza, 2012.

NEIVA, Pedro; IZUMI, Maurício. Os "doutores" da federação: formação acadêmica dos senadores brasileiros e variáveis associadas. Rev. Sociol. Polit., Curitiba, v. 20, n. 41, p.171-192, fev. 2012.

NEIVA, Pedro; IZUMI, Maurício. Perfil profissional e distribuição regional dos senadores brasileiros em dois séculos de história. Revista Brasileira de Ciências Sociais, São Paulo, v. 29, p. 165-188, 2014.

NORRIS, Pippa. Passages to Power: Legislative recruitment in advanced democracies. Cambridge: Cambridge University Press, 1997.

NORRIS, Pippa. Recrutamento político. Rev. Sociol. Polit., Curitiba, v. 21, n. 46, p. 11-32, jun. 2013.

NORRIS, Pippa; LOVENDUSKI, Joni. United Kingdom. In: NORRIS, Pippa. Passages to Power: Legislative recruitment in advanced democracies. Cambridge: Cambridge University Press, 1997.

ORSATO, Andréia. " Como mulher e deputada": a presença feminina na Assembléia Legislativa do Rio Grande do Sul (1951-2011). Tese (Doutorado em Ciência Política) - Instituto de Filosofia e Ciências Humanas, Universidade Federal do Rio Grande do Sul, Porto Alegre, 2013.

PALERMO, V. Como se Governa o Brasil? O Debate sobre Instituições Políticas e Gestão de Governo. Dados, v. 43, n. 3, 2000.

PERISSINOTTO, Renato Monseff; BOLOGNESI, Bruno. Electoral Success and Political Institutionalization in the Federal Deputy Elections in Brazil (1998, 2002 and 2006). Brazilian Political Science Review, São Paulo, v.4, n.1, p. 10-32, 2010.

PERISSINOTTO, Renato Monseff; BRAUNERT, Mariana B. A direita, a esquerda e a democracia: os valores políticos dos parlamentares paranaenses (1995-2002). Opinião Pública, Campinas, v. 12, n.1, p. 114-135, 2006.

PERISSINOTTO, Renato Monseff; COSTA, Luiz Domingos; TRIBESS, Camila. Origem social dos parlamentares paranaenses (1995-2006): alguns achados e algumas questões de pesquisa. Sociologias, Porto Alegre, v. 22, p. 280-313, 2009.

PERISSINOTTO, Renato Monseff; MIRÍADE, Angel. Caminhos para o parlamento: candidatos e eleitos nas eleições para deputado federal em 2006. Dados, Rio de Janeiro, v. 52, n. 2, p. 301333, jun. 2009.

PESSOA JÚNIOR, José Raulino Chaves de. Entre as bases e o governo: trajetória política de deputados estaduais da Região dos Inhamuns. 2011. Dissertação (Mestrado em Sociologia) departamento de Ciências Sociais, Universidade Federal do Ceará, Fortaleza, 2011.

POWER, Timothy J.; ZUCCO, Cesar Jr. (org.). O congresso por ele mesmo: autopercepções da classe política brasileira. Belo Horizonte: Editora UFMG, 2011. 
PRATI, Luana Puppin. Perfil social, recrutamento e trajetórias políticas: uma análise dos representantes do legislativo estadual Capixaba, 1986-2010. 2013. Dissertação (Mestrado em Ciências Sociais) - Centro de Ciências Humanas e Naturais, Universidade Federal do Espírito Santo, Vitória, 2013.

PRATI, Luana Puppin; PESSINE, K. M.; CAMPOS, M. M. Perfil socioeconômico dos legisladores subnacionais: o que a reeleição trouxe de mudanças nas últimas legislaturas da Assembleia Legislativa do Estado do Espírito Santo. Agenda Política, São Carlos, v. 4, n. 3, p. 65-89, 2016.

PUTNAM, Robert. The comparative study of political elites. Englewood Cliffs: Prentice-Hall, 1976.

RODRIGUES, Jean Carlos; DE SOUSA, Phabula Saylla Aires. GEOGRAFIA E ELEIÇÃO. Revista Tocantinense De Geografia, v. 6, n. 11, p. 125-141, 2017.

RODRIGUES, Leôncio Martins. Quem é quem na Constituinte: uma análise sócio-política dos partidos e deputados. São Paulo: OESP, 1987.

RODRIGUES, Leôncio Martins. Mudanças na classe política brasileira. São Paulo: Publifolha, 2006.

RODRIGUES, Leôncio Martins. Partidos, ideologia e composição social: um estudo das bancadas partidárias na Câmara dos Deputados. São Paulo: Edusp, 2002.

RODRIGUES, Leôncio Martins. Pobres e ricos na luta pelo poder: novas elites na política brasileira. 1. ed. Rio de Janeiro: Topbooks, 2014.

SAMPAIO, Pedro Henrique Cavalcanti. Profissionalização legislativa e padrão de carreira dos deputados estaduais das Assembleias do Rio de Janeiro e de Minas Gerais. 2012. Dissertação (Mestrado em Administração Pública e de Empresas) - Fundação Getúlio Vargas, Rio de Janeiro, 2012.

SANTOS, F. G. M. O Poder Legislativo nos Estados: Diversidade e Convergência. 1. ed. Rio de Janeiro: Editora FGV, 2001.

SILVA, P. C.; BORGES, Tiago Daher Padovezi . Quem são os Deputados Estaduais Brasileiros? Uma análise dos eleitos em 2014. Cadernos Adenauer, São Paulo, v. 18, p. 103-118, 2017.

SILVEIRA, A. O perfil do poder legislativo da capital e do estado de Mato Grosso (1983/2004). Revista de Sociologia e Política, Curitiba, v. 17, p. 271-299, 2009.

SILVEIRA, Luana Borges da. Elas representam quem, cara pálida? Um estudo sobre a representação política das deputadas estaduais do rio grande do sul (2007-2011). 2014. Dissertação (Mestrado em Ciências Sociais) - Faculdade de Filosofia e Ciências Humanas, Pontifícia Universidade Católica do Rio Grande do Sul, Porto Alegre, 2014.

SIMONI JUNIOR, S.; MUCINHATO, R. M. D.; MINGARDI, L. A elite parlamentar brasileira de 1995 a 2010: até que ponto vai a popularização da classe política? Colombia Internacional, Bogotá, v. 87, p. 109-143, 2016.

SOUZA, Augusto Carvalho; BASTOS, Ronaldo Rocha; VIEIRA, M. de T. Análise de Correspondência Simples e Múltipla para Dados Amostrais Complexos. In: SINAPE, 19. 2010, São Pedro, SP. Anais [...] São Pedro, SP: ABE; UFMG, 2010. p.1-6.

STONE, Lawrence. Prosopografia. Rev. Sociol. Polit., Curitiba, v.19, n. 39, p.115-137, jun. 2011. 
TAROUCO, Gabriela; MADEIRA, Rafael M. Os partidos brasileiros segundo seus estudiosos: análise de um expert survey. Civitas, Porto Alegre, v. 15, n. 1, p. 24-39, jan./mar. 2015.

TAROUCO, Gabriela; MADEIRA, Rafael M. Partidos, programas e o debate sobre esquerda e direita no Brasil. Revista de Sociologia e Política, Curitiba, v. 21, n. 45, p. 149-165, 2013.

UNZUE, Martín. A universidade na trajetória dos parlamentares brasileiros. Rev. Bras. Ciênc. Polít., Brasília, n. 8, p. 13-46, ago. 2012.

WEBER, Max. Escritos Políticos. São Paulo: WMF Martins Fontes, 2014.

ZIEGMANN, A. B. Perfil sociopolítico e decisões legislativas na $15^{\mathrm{a}}$ Legislatura das Assembleias legislativas do Paraná, São Paulo e Minas Gerais (2003-2007). 2011. Dissertação (Mestrado em Ciência Política) - Instituto de Filosofia e Ciências Humanas, Universidade Estadual de Campinas, Campinas, 2011.

Artigo recebido em: 2019-07-31

Artigo aceito para publicação em: 2019-08-13 